\title{
Specifics of Snow Avalanche Regime in the Mountainous Regions of the Chechen Republic and the Republic of Ingushetia
}

\author{
Kondratyeva N.V. \\ Department for Force of Nature Research \\ High Mountain Geophysical Institute, Rosgydromet \\ Nalchik, Russia \\ e-mail: kondranyeva_nat@mail.ru \\ Bekkiyev M.Yu. \\ Director of \\ High Mountain Geophysical Institute, Rosgydromet \\ Nalchik, Russia \\ e-mail:mbekk@mail.ru \\ Khuchunayeva L.V. \\ Department for Force of Nature Research \\ High Mountain Geophysical Institute, Rosgydromet \\ Nalchik, Russia \\ e-mail: khuchunaeval@mail.ru \\ Uzdenova A.B. \\ Department for Force of Nature Research \\ High Mountain Geophysical Institute, Rosgydromet \\ Nalchik, Russia \\ e-mail: albino_uzdenova@mail.ru
}

\author{
Agzagova M.B. \\ Department for Force of Nature Research \\ High Mountain Geophysical Institute, Rosgydromet \\ Nalchik, Russia \\ e-mail: madrid-nal@yandex.ru
}

Tumgoyeva Kh.A.

Department of Algebra and Geometry

Chechen State University

Grozny, Russia

e-mail: hadiga-71@mail.ru

Muratov I.A.

Department for Force of Nature Research

High Mountain Geophysical Institute, Rosgydromet

Nalchik, Russia

e-mail: inal.muratov@mail.ru

Gergokova Z.Zh.

Department for Ecological Research

High Mountain Geophysical Institute, Rosgydromet

Aushiger, Russia

e-mail:zayna.gerg@mail.ru

\begin{abstract}
Avalanches are hazardous natural phenomena, just like earthquakes, floods, mudslides, etc. Every year, avalanches claim lives of hundreds of people and destroy economically important facilities, mainly motor roads and railroads. Prediction of the danger of avalanche is a part of a complex of measures aimed at protection of population and facilities in mountainous regions from avalanches.
\end{abstract}

Keywords-meteorological observations, snow cover, avalanche, forecast, danger of avalanche, station

\section{INTRODUCTION}

In 2010, in accordance with the Federal targeted program for development of North Caucasus resorts, the Government of the Russian Federation stated their intention to build five modern mountain ski resorts of European class during the next 10 year. It assumes conducting detailed avalanche research through both studied regions and those where the avalanche activity has not been studied to a sufficient degree.

Due to this, there is a necessity to study the avalanche formation processes and to plot maps of the danger of avalanche, that is, to systematize all the available data on snow avalanche regime in the territory of the Chechen Republic and the Republic of Ingushetia.

Initial data for systematization and analysis of the danger of avalanche in the mountainous zones of the Chechen Republic and Ingushetia were: Materials obtained from expeditionary, traversing and stationary observations of avalanches in the mountains of Eastern Caucasus; data from literature sources (monographs, papers), library and map material, space photographs data, etc.

\section{RESULTS}

The Republic of Ingushetia and the Chechen Republic (Chechnya) are located at the mountain slopes of East Caucasus. Their mountainous portion comprises the territory of Bokovoy, Skalisty, Pastbischny and Lesistyi ranges, whose slopes are avalanche-prone. Climate of Ingushetia is continental. Average January temperatures range from $-3^{\circ} \mathrm{C}$ to $-10^{\circ} \mathrm{C}$, average July temperatures are from $+21^{\circ} \mathrm{C}$ to $+23^{\circ} \mathrm{C}$. There are up to $1200 \mathrm{~mm}$ of precipitation annually [1]. Climate of Chechnya is very diverse: from dry and hot in the north to overly humid in the south (high-altitude zone). The highland is 
characterized with a low heat supply and a large amount of precipitation (over $1000 \mathrm{~mm}$ ) [1,2].

Avalanche forecasts are created following a region- and cluster-specific methodologies that determine the algorithm for identifying the danger of avalanche [4-7].

From long-term observations at meteorological stations located in highland parts of the republics: Shatoy (528 masl), Vedeno (715 masl), Botlikh (980 masl), Armkhi (1200 masl), Kazbegi (1744 masl), Sulak Highlands (2923 masl), Kazbegi Highlands (3653 masl), as well as from independent measurements and survey of local inhabitants. Average annual temperatures vary depending on the absolute height from $-6.1^{\circ}$ $\mathrm{C}$ to $+9.8^{\circ} \mathrm{C}$, while the annual precipitation fluctuates in the range $407-1404 \mathrm{~mm}$. During the cold period (NovemberMarch) the average temperature is from $-12.7^{\circ} \mathrm{C}$ to $+1.4^{\circ} \mathrm{C}$, the total amount of precipitation is $50-370 \mathrm{~mm}$.

Experience from long-term studies of avalanches allowed establishing certain regularities in the avalanche formation process, revealing the leading factors in avalanche collapse and evaluating various parameters of the phenomenon [8-11].

The evaluation of relief structure as conditions of avalanche formation was based on morphological and morphometric characteristics: slope angles, depth and density of breakdown, absolute and relative height of the slopes (Figure 1)

Due to a fact that the avalanche formation mode depends on the height and activity of avalanche catchments, the mountainous portion of Chechen Republic and Ingushetia is divided into three zones: low hill $(600-1000 \mathrm{~m})$, middle altitudes (1000-2500m) and highlands (over $2500 \mathrm{~m})$. Avalanches may form in any of the three. In Figure 2 there is a map chart of highland avalanche formation zones plotted by the authors

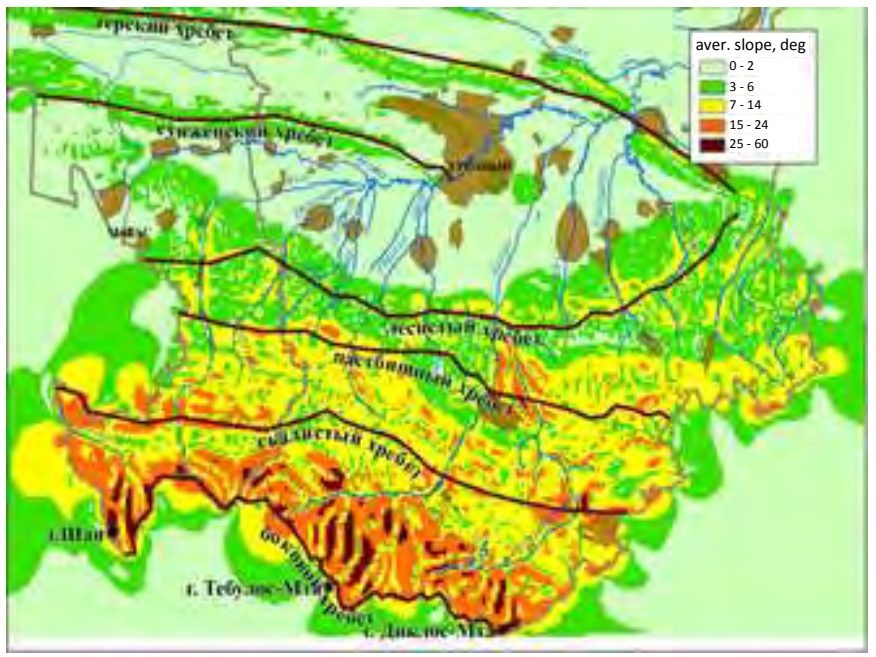

Fig. 1. Map chart of the average slopes in the Chechen Republic and the Republic of Ingushetia

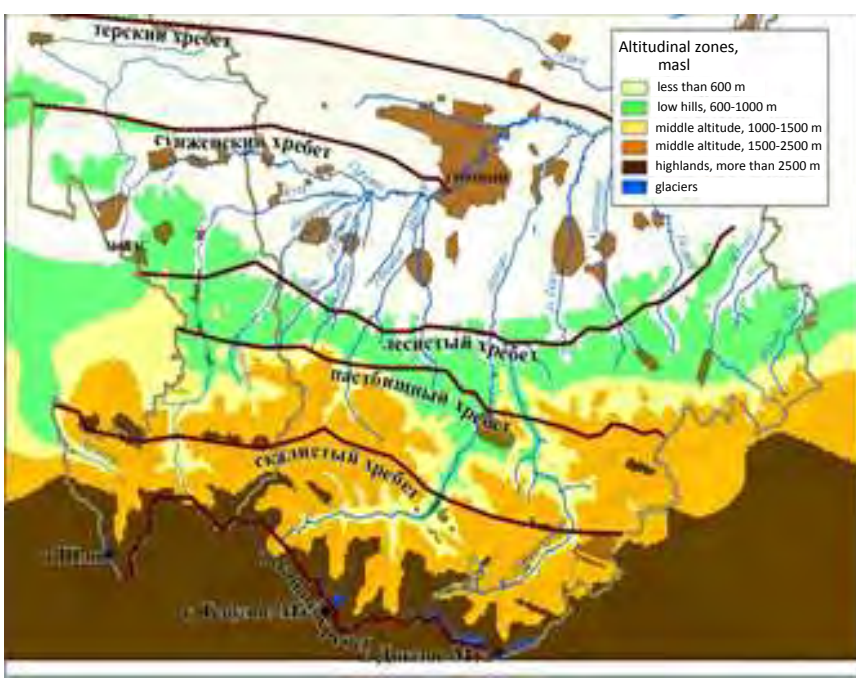

Fig. 2. A map of highland avalanche formation zones of the Chechen Republic and Ingushetia

Evaluation of natural components revealed that the main factors influencing the avalanche formation mode are mountainous relief and snow cover thickness [2-3].

Analysis of Figures 1, 2 have shown that in the catchment basins of rivers Sunzha (Assa, Fortanga, Gehi, Martan, Chatyargun, Sharoargun, Bass, Khulkhulau, Game) and Aksaut, the zone of avalanche activity covers a broad range of heights (from $600 \mathrm{~m}$ to $4500 \mathrm{~m}$ ) and values of slope steepness of slopes (from $15^{\circ}$ to $46^{\circ}$ ). The most avalanche-hazardous are the slopes with the steepness of $25^{\circ}-35^{\circ}$ : they comprise over $50 \%$ of all the avalanche sites, $40 \%$ more avalanche sites are located at the slopes with a steepness of $35^{\circ}-46^{\circ}$. Thus, in this catchment basin, $90 \%$ of the avalanche-formation centers are in the slopes with steepness of $25^{\circ}-46^{\circ}$. Slopes with the steepness of $15^{\circ}-25^{\circ}$ and $46^{\circ}-75^{\circ}$ show less avalanche activity: They cover only $10 \%$ of all the avalanche sites.

The main climatic parameters that influence the development of avalanche processes are regime and amount of solid precipitation.

\section{A. Snow cover}

Formation of the snow cover within the highland zone $2000 \mathrm{~m}$ and higher happens in October. In November, snow covers the Skalisty and Pastbischny ranges and a part of the Lesisty range (Black Mountains). However, stable snow cover at mountains of $700 \mathrm{~m}$ and higher is established only in the middle of December.

Snow cover in the southern highland part of both republics is permanent. In the summer, the snow line in the highlands of Chechnya and Ingushetia is kept as a height of $3800 \mathrm{~m}$ thanks to the continental nature of the climate. Even in July, the warmest month, snow does not melt there. Precipitation falls out as sleet and a mix of rain and snow during the day, and as hard snowflakes during the night. During the summer months, the snow masses affected by a thaw break loose from the steep slopes in the form of snowbreaks and avalanches and go down beyond the snow line to feed mountain rivers. 
According to the conducted analysis of accumulated data, the number of days with stable snow cover in the highland zone of Chechnya and Ingushetia (above 2500 masl.) is 200 or more. In the middle altitudes (1500 - 2500 masl) it is $100-200$, in the low hills (1000 - 1500 masl) and (600 - 1000 masl) - 50 - 100 (Figure 3).

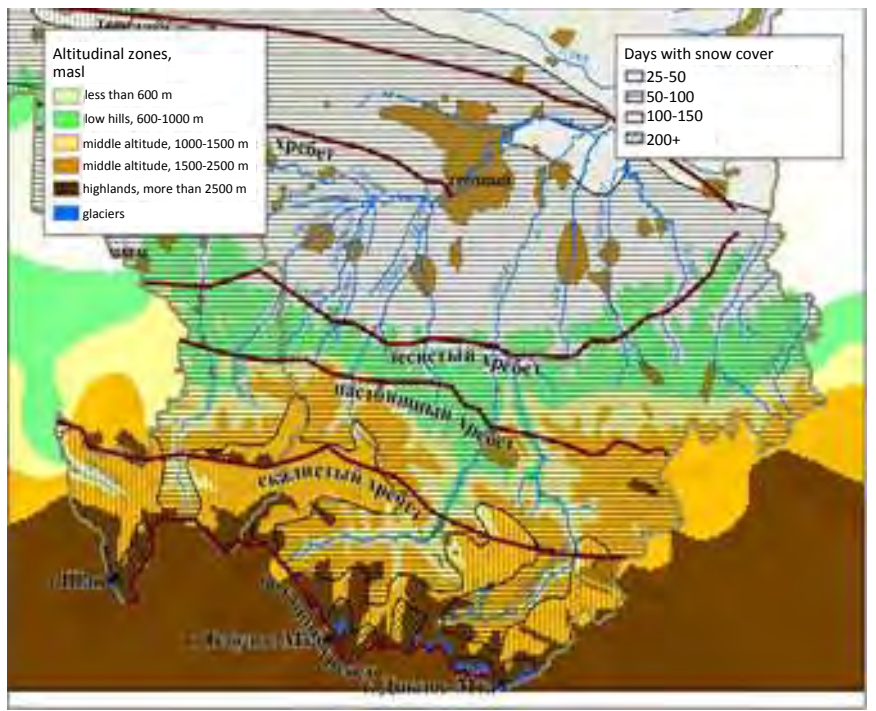

Fig. 3. Map chart of regions according to the number of stable snow cover

The total amount of annual precipitation increases with the absolute elevation. The ratio of solid precipitation also increases with the absolute elevation. At an elevation of over $2500 \mathrm{~m}$, the total amount of the solid precipitation reaches $160 \mathrm{~cm}$ annually. In the zone from $1000 \mathrm{~m}$ to $2500 \mathrm{~m}$, the total annual amount of the solid precipitation varies between $10 \mathrm{~cm}$ and $120 \mathrm{~cm}$, depending on exposure of the slopes. In the low hills $(600-1000 \mathrm{~m})$ the maximum amount of the solid precipitation reaches $10 \mathrm{~cm}$ (Figure 4 ).

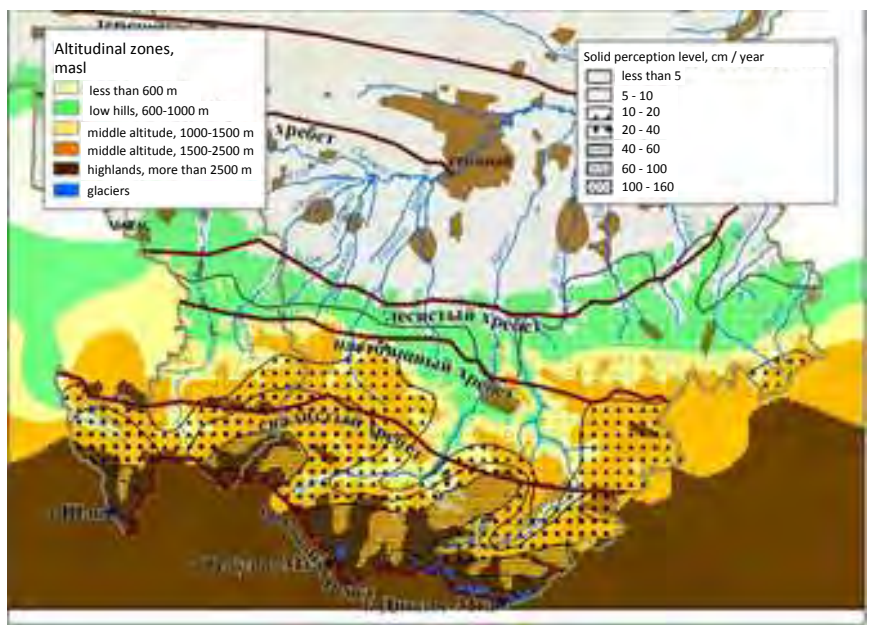

Fig. 4. Map chart of regions according to the total annual amount of solid precipitation as a function of on absolute elevation

The average maximum height of the snow cover at mountain heights of below $1000 \mathrm{~m}$ is $10 \mathrm{~cm}$, at the heights between $1000 \mathrm{~m}$ and $1500 \mathrm{~m}$ it is $40 \mathrm{~cm}$, between $1500 \mathrm{~m}$ and $2500 \mathrm{~m}$ it is $70 \mathrm{~cm}$, and above $2500 \mathrm{~m}$ it is at least $70-100 \mathrm{~cm}$.
In some locations, the height of snow banks reaches $1-1.5 \mathrm{~m}$ or higher (Figure 5).

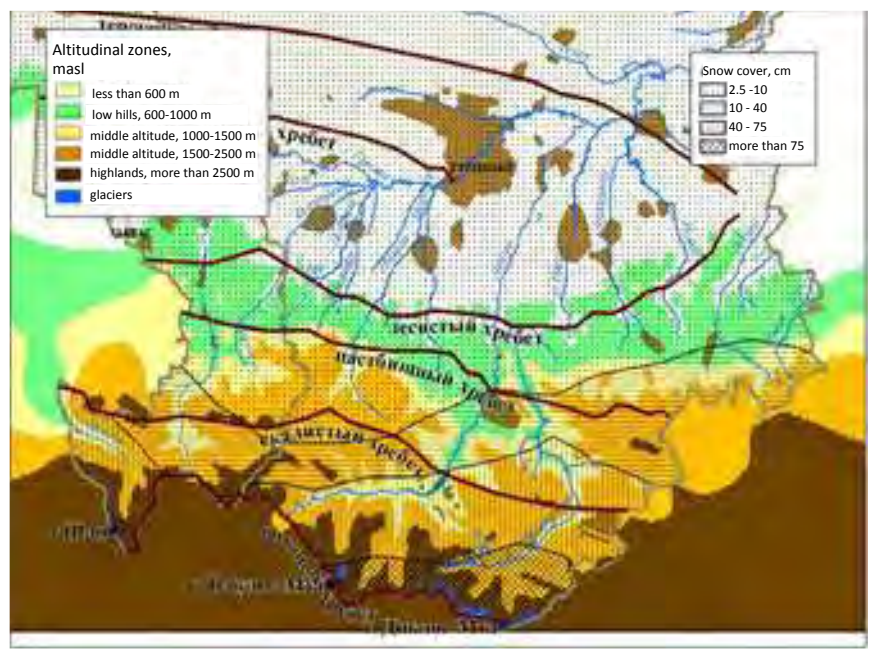

Fig. 5. Map chart of regions of Chechnya and Ingushetia according to the average snow cover thickness

According to our scheme of evaluation of the mountainous relief and snow cover at the slopes as the main factors in avalanche formation in the territory of the republics [12], there are five main types of relief depending on the degree of roughness and being linked to different height zones.

\section{B. Zone of badland and poorly broken relief of alpine and subalpine highlands}

The zone located above $2500 \mathrm{~m}$ with a relative altitude of $1000-1,500 \mathrm{~m}$ and slope steepness over $30^{\circ}$, with a dense network of avalanches (over 6 avalanches per 1 linear kilometer of valley floor, annual avalanching, and over 10 avalanches from a single avalanche catchment per 10 years).

\section{Zone of badland and averagely broken middle altitude mountains}

The zone with the elevations in a range of $1500-2500 \mathrm{~m}$, relative altitude of $1000-1200 \mathrm{~m}$, slope steepness of $20-40^{\circ}$, sparse network of avalanches (from 1 to 6 avalanches per 1 linear kilometer of valley bottom, from 1 to 10 avalanches from a single avalanche catchment per 10 years).

\section{Zone of moderately broken middle altitude mountains}

The zone with the elevations in a range of $1000-1500 \mathrm{~m}$, relative altitude of $500-800 \mathrm{~m}$, slope steepness of $20-25^{\circ}$, separate avalanche sites (about 1 avalanche per 1 linear kilometer of valley bottom, 1 avalanche from a single avalanche catchment per 10 years).

\section{E. Zone of badlands and poorly broken low hills}

The zone with elevations from 600 to $1000 \mathrm{~m}$, soft forms of relief, relative altitudes of $200-600 \mathrm{~m}$, slope steepness of 15 $30^{\circ}$, rarefied network of avalanches. There is almost no danger of avalanche. There are individual avalanches in extremely snowy winter (the danger of avalanche may increase due to cutting of forest, removal of soil from the slopes, etc.). 


\section{F. Zone of poorly broken low hills}

The zone with elevations of $400-600 \mathrm{~m}$, relative altitude of 100 - 200m, slope steepness under $15^{\circ}$, small amplitude of height breakdown and moderate snow accumulation. There are no permanent avalanche sites, but they may arise during some extremely snowy winters due to cutting of forest, removal of soil from the slopes or erosion of plant cover.

Taking into consideration the above mentioned regularities, as well as archive data analysis and results from traversing surveys in the period from August to September of 2017, map charts of avalanches in the territories of the Chechen Republic and Ingushetia were plotted.

In Figure 6 there is a map chart of regions according to the number of avalanches from a single avalanche catcher per 10 years for the territory of Chechnya and Ingushetia.

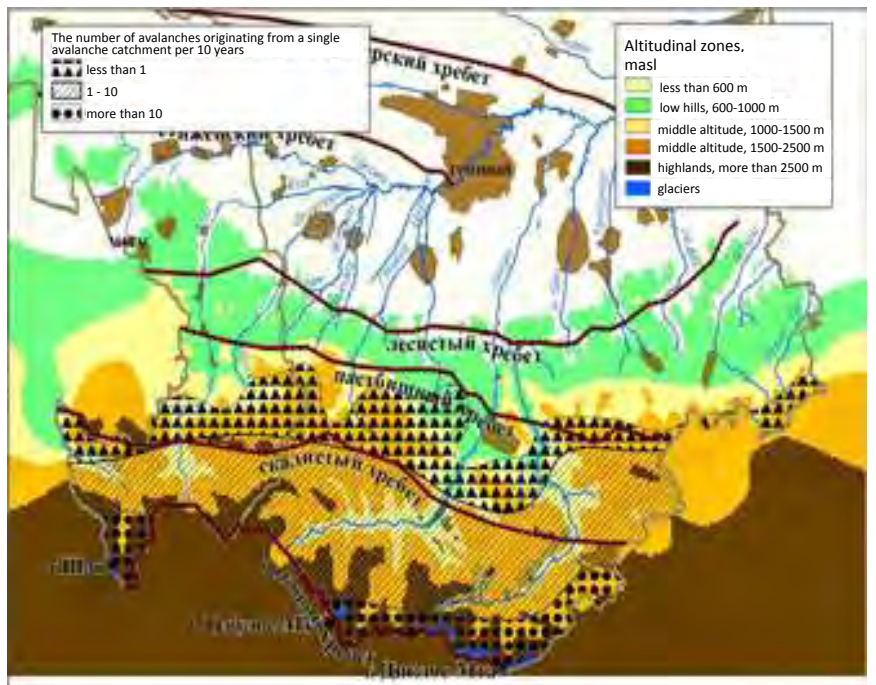

Fig. 6. Map chart of regions according to the number of avalanches from a single avalanche catcher per 10 years for the territory of Chechnya and Ingushetia

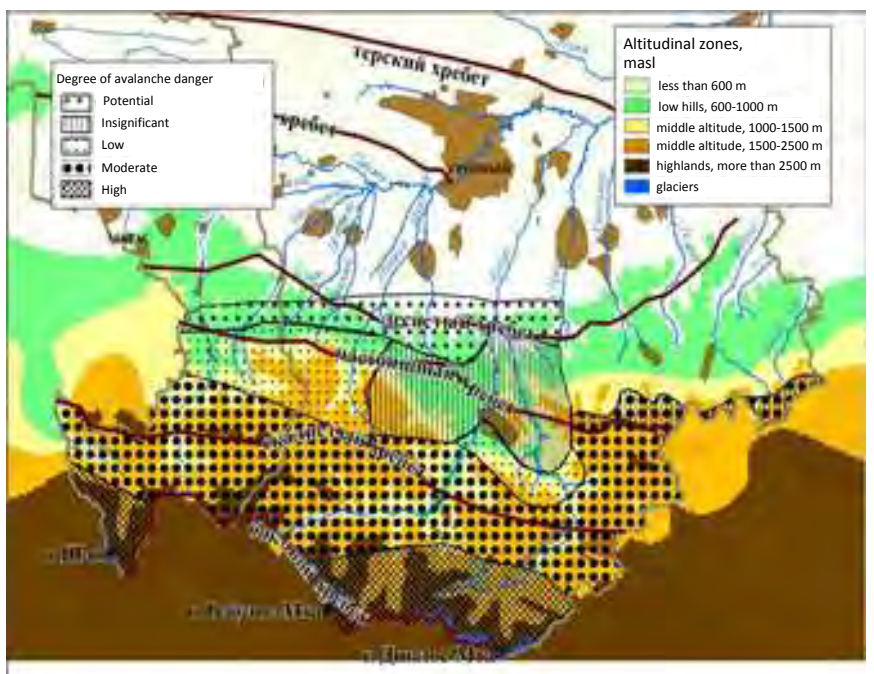

Fig. 7. Map chart of the regions according to the degree of avalanche activity in the territories of Chechnya and Ingushetia
Analysis of material from first-hand observations of avalanche breaking, climatic conditions and relief types allowed conducting zoning [3] of the studied territory according to a degree of danger of avalanche: high, moderate, low, insignificant, potential (Figure 7).

\section{G. High avalanche danger zone}

Avalanches break down annually, 2-3 times or more. The thickness of avalanches per 1 linear kilometer of valley bottom is over 6 , the volume of maximum avalanches reaches 16 thousand $\mathrm{m}^{3}$. This zone comprises highland part of the Bokovoy range - the region of the Shansky massif (Shan mountain $4451 \mathrm{~m}$ ) in the west and a region of $45 \mathrm{~km}$ long in the east (Diklos-Mta mountain $-4285 \mathrm{~m}$ ) and is related to upper reaches of Shondor and Sharoargun rivers. The strongest danger of avalanche is characteristic of the upper reaches of Sharoargun river: up to 10 avalanche sites per 1 linear kilometer of valley bottom. The volume of avalanche deposit may reach 100 thousand $\mathrm{m}^{3}$ and more, while the maximum impact force against a fixed obstacle is $103 \mathrm{t} / \mathrm{m}^{2}$.

The average snow cover depth at the mountain slopes reaches $60 \mathrm{~cm}$, while in snowy winters it may exceed $2 \mathrm{~m}$. During such winters there is a surge in the danger of avalanche, there are powerful sporadic avalanches that cause a significant damage to the population of the mountainous regions. A zone of high avalanche danger comprises the altitudinal belt of 2500 $4000 \mathrm{~m}$. Breakdown of the first avalanches in the lower part of the zone $(2500-3000 \mathrm{~m})$ starts in October and coincides with establishment of a stable snow cover throughout the altitudinal belts. The number of days with a stable snow cover reaches 250 . During the winter, there are avalanches breaking down consisting of fresh snow due to intense snowfall and wind transport resulting in increased snow cover depth of $50 \mathrm{~cm}$ and more at slopes. The number of snowstorm days may reach 45 (Sulak station, highlands, 2923m).

Avalanche formation is also significantly influenced by foehns and thaws as they facilitate avalanche formation of slush. The number of foehn days at a height of $2923 \mathrm{~m}$ may reach 100. The period of avalanche hazard lasts for 6.5 months in the region and ends in May.

Avalanches, especially sporadic ones, bring large losses to regional forestry and are a source of great danger during construction of motor roads and other infrastructural and economic facilities.

\section{H. Zone of moderate avalanche activity}

The zone comprises the altidudinal belt of $1500-2500 \mathrm{~m}$. Here, more than $16 \%$ of avalanche catchments may produce 1 avalanche annually, $6 \%$ produce 1 avalanche every $2-3$ years, $50 \%$ produce 1 avalanche every 3 - 10 years and $28 \%$ produce sporadic avalanches. The avalanche density varies from 1 to 6 per 1 linear kilometer of valley bottom, the maximum volume of the avalanches is from 10 to 50 thousand $\mathrm{m}^{3}$, while the force of impact against a fixed obstacle reaches $146 \mathrm{t} / \mathrm{m}^{2}$.

The territory with moderate avalanche activity stretches as a wide stripe from western to eastern borders of the republic and comprises northern slopes of Bokovoy and Skalisty ranges. The width of this stripe depends on the structure of relief, the amount of precipitation, duration of snow cover period, 
movement of meteorological elements and comprises from 6 to $20 \mathrm{~km}$.

The upper limit passes along the northern slopes of the Bokovoy range and its branches at a height of $2500 \mathrm{~m}$. The lower limit is at the elevation of $1500-1700 \mathrm{~m}$ and may be traced along the northern and southern slopes of the Skalisty range. The number of stable snow cover days amounts to 112 (Kyryz station - 2071m) and may reach 180 at a height of $2500 \mathrm{~m}$. The snow cover appears in early December and retreats in early March The period of avalanche hazard starts in the second half of December and lasts for about 3 months. Sporadic avalanches pose a significant danger; they are formed once every $3-10$ years as a result of heavy and prolonged snowfall. Up to $85 \%$ of avalanches consist of wet snow. The most dangerous with respect to avalanches is the upper boundary of the region. Breaking of avalanches poses a significant danger for motor transport and tourists, causing obstruction of roads and nature trails.

\section{Zone of low avalanche activity}

The zone is located lower than the previous one, at the elevations of 1000 - 1500, and may be traces on the slopes of Pastbischny and Skalisty ranges as separate areas. The first area of this zone stretches for $40 \mathrm{~km}$ from the western borders of Ingushetia to the south-east along the slopes of Pastbischny range, comprising the central part of the Skalisty range. The second area stretches as a narrow 4-kilometer-wide and 80-kmlong band along the northern slopes of the eastern ends of Skalisty and Pastbischny ranges.

During the cold period of the year (November-February), there is a relatively low amount of precipitation $(74 \mathrm{~mm})$ in the zone of low avalanche activity, determining mild avalanche activity on the slopes. Thus, $80 \%$ of avalanche sites are capable of forming 1 avalanche every 5 - 10 years, and only $5 \%$ of sites produce 1 avalanche annually. The rest $15 \%$ of avalanche sites are capable of producing only sporadic avalanches. The avalanche density is on average about 1 per 1 linear kilometer of valley bottom. Maximum volumes of avalanche do not exceed $1000 \mathrm{~m}^{3}$, at that, usually the avalanched do not each the valley bottom. The number of days with the danger of avalanche is about 70 per year.

\section{J. Zone of insignificant avalanche activity}

The zone is confined to low hills and is located in the altitudinal belt of $600-1000 \mathrm{~m}$ with low absolute and relative elevation. The lower boundary of this zone is traced along the northern slopes of the Pastbischny range in the west to the border of the Chechen Republic in the east. This zone is characterized with short duration of the snow cover period (50 - 60 days per year). The stable snow cover is established in the end of November, reaches maximum thickness of $10-15 \mathrm{~cm}$ in January and February and disappears in the end of March (Sovetskoye station $-530 \mathrm{~m}$ ).

Due to relief and snowiness conditions, there are virtually no avalanches in this zone. However, during snowy winters, areas of slopes without vegetation are capable of producing wet avalanches and snowslides with a volume of up to $500 \mathrm{~m}^{3}$. Presence of dense forest and bush reduces the avalanche formation dramatically. The forest facilitates uniform distribution of the snow cover through the slopes and reduces the wind transport of snow.

\section{K. Zone of potential avalanche hazard}

The zone is located in the altitudinal belt of $400-800 \mathrm{~m}$ and stretches as a narrow band seven kilometers wide from the west to the east along the northern and southern slopes of the Lesisty range, covering its branches.

The slopes of the Lesisty range have soft rounded contours typical of low hills. The snow cover is unstable, disappears in mid-March, its duration is about 50 days per year. This zone is currently avalanche safe, however, some areas on the slopes may become avalanche-prone due to cutting of forests, removal of soil, clearing the slopes of vegetation or other works that reduce the roughness of the slopes.

In the rest of the territory, there are no avalanches.

Figure 8 shows a map chart reflecting a dependence of avalanche formation factors on absolute elevation.

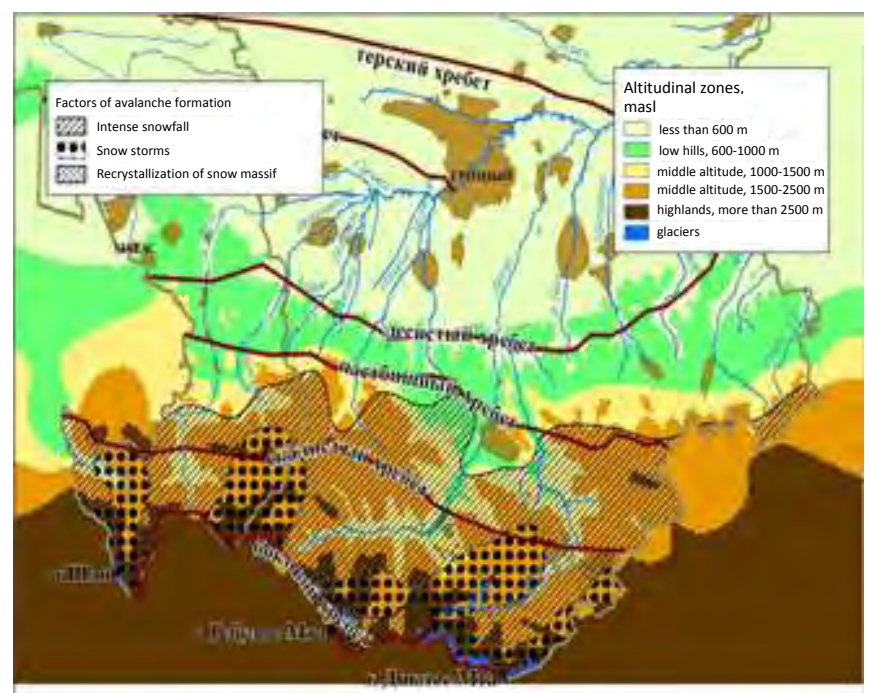

Fig. 8. Map chart of the zones reflecting the factors of avalanche formation in the territories of Chechnya and Ingushetia

\section{III.CONCLUSION}

A study of snow avalanche regime in the mountainous regions of the Chechen Republic and the Republic of Ingushetia was conducted. Seasonal distribution of snow accumulation was obtained for the studied territory. Average annual temperatures vary from $-6.1{ }^{\circ} \mathrm{C}$ to $+9.8{ }^{\circ} \mathrm{C}$ depending on elevation, while the annual precipitation varies in the range of $407-1404 \mathrm{~mm}$. During the cold period (November-March) the average temperature is from $-12.7^{\circ} \mathrm{C}$ to $1.4^{\circ} \mathrm{C}$, the total amount of precipitation is $50-370 \mathrm{~mm}$.

\section{References}

[1] V.V. Razumov, A.Kh. Adzhiyev, N.V. Razumova, N.V. Kondratyeva, A.Ya. Glushko, S.I. Shagin, A.P. Pritvorov, A.G. Kolychev, M.A. Shapovalov, Dangerous natural processes in Northern Caucasus, Moscow, 2013, p. 319.

[2] V.V. Razumov, M.I. Tlisov, E.N. Molchanov, N.V. Razumova, S.I. Grigorov, B.N. Alekseyev, A.I. Yunak, B.M. Sheremetyev, Evaluation of 
natural potential and environmental state of the territory of the Chechen Republic.Saint Petersburg: Hydrometeoizdat, 2001, p. 158.

[3] National Inventory of Avalanches in the USSR. European Portion. Caucasus. Leningrad: Hydrometeoizdat, 1989.

[4] A. Judson, Leaf C.F., G.E. Brink, "A process-oriented model for simulating avalanche danger”, J. Glaciol, vol. 26, pp. 53-63, 1994.

[5] E. Brun, E. Martin, V. Simon, C. Gendre, C. Coleou, "An energy and mass model of snow cover suitable for operational and avalanche forecasting", J. Glaciol., vol. 35 (121), pp. 333-342, 1989.

[6] P. FFhn. An overview of avalanche forecasting models and methods. Oslo, NGI, Pub.N 203, 1998, pp. 19-27.

[7] H. Leuthold, B. Allgower, R.Meister, "Visualization and analysis of the Swiss avalanche bulletin using GIS", Banff, Canada. pp.35-40, [Proceedings of the International Snow, Science Workshop, p.252, 1997].
[8] W. Ammann, O.Buser, U Vollenwyder, Lawinen. Basel: Birkhauser V., 1997, pp.170-178.

[9] D.M. McClung, and P. Schaerer, The Avalanche Handbook. The Mountaineers, Seattle, Washington, U.S.A., 1993, p. 271

[10] Observation Guidelines and Recording Standards for Weather, Snowpack and Avalanches Prepared by the Canadian Avalanche Association. 1995 ISBN 0-9699758-0-5

[11] T. Glazovskaya, "Global distribution of snow avalanches and possible change of avalanche activity in the Northern Hemisphere due to the climatic change", Annals of Glaciology, Cambridge, K, vol. 26, pp. 337 342, 1998.

[12] An Atlas of Natural and Technogenic hazards and risks of the Russian Federation. Southern Federal Region, S.K. Shoygu Ed. Moscow: Design. Information. Cartography, 2007, p. 386. 